\title{
A Global View of Psychology in the Manager's Work
}

\author{
Emilia Gresakova ${ }^{1, *}$, Darina Chlebikova ${ }^{2, b}$, \\ ${ }^{1}$ University of Zilina, Faculty of Operation and Economics of Transport and Communications, \\ Department of Economics, Univerzitna 1, 01026 Zilina, Slovak republic \\ ${ }^{2}$ University of Zilina, Faculty of Operation and Economics of Transport and Communications, \\ Department of Economics, Univerzitna 1, 01026 Zilina, Slovak republic
}

\begin{abstract}
The aim of the paper is to define a global view of the role of psychology in the manager's work. By analyzing managerial work in terms of psychology and research in the field of application knowledge of psychology between managers and employees of the world's leading IT company. We reviewed their views on selected areas to improve their internal motivation and satisfaction, which leads to improvements in their work. To explore the motivation of our employees, we decided to use the knowledge of the International Model of Job Characteristics, which is one of the most popular in this area. This model and related survey method come from the 1970s. The model was designed by Richard Hackman and Greg Oldham. It is based on previous approaches called Job extensions based on adding responsibilities of the same difficulty. Oldham and Hackman tried to identify the global characteristics of internal motivation work in these older models and to explore their implications. Oldham and Hackman believed that employees were doing well under the influence of these factors while being internally motivated - having a sense of happiness and happiness. This feeling motivates them to perform better. Characteristic model work presents five global aspects influencing internal motivation: skills variability, job identity, job importance, autonomy, feedback.
\end{abstract}

\section{Introduction}

The success of companies depends largely on the skills and abilities of their managers, who fulfill the plan of the company through managerial functions. Managers are trying to get the best out of their employees to achieve business goals. The difficulty of this profession lies mainly in the combination of technical and soft aspects of management [1].

Empirical data are employed to support the claim that what is coherent to workers affected by moral awareness that algorithmic management is immoderatelyand companies indifferent [2]. The basic assumption of traditional finance is that all market participants, as well as the market itself, behave rationally to maximize their benefits [3]. Contemporary market reality indicates that traditional economic theories are failing and there is a need to reassess them by a behavioural approach that includes both, sociological and psychological aspects [4]. It is precisely in developing the manager's soft

*Correspondingauthor: emilia.gresakova@fpedas.uniza.sk 
competences that knowledge from the field of psychology can be beneficial. This science of human experience and behavior helps the manager not only to better understand the behavior and actions of employees [5]. However according to [6] the most important benefit should be provided by a solution powered by AI. Through this article we want to point out the importance of psychology in the work of managers. Since management represents a set of knowledge from various scientific disciplines (eg economics, mathematics, sociology, psychology, etc.), the managerial function can be characterized from different points of view [7].

On the one hand, the manager is the one who manages the business in accordance with the objective of making profit, ensuring the competitiveness and good market position of the business. On the other hand, he works with and through people. Therefore, we could say that he is a person who can plan to organize, delegate tasks, communicate correctly, lead his employees, evaluate, support their development and know how to motivate them [8].

Ultimately, it can capitalize on the strengths of its employees to meet the company's goals. These assumptions can be used with the help of the right employee motivation. Nowadays, psychology plays a big role in the work of a manager when human potential is the most important asset of a company [9]. By knowing the motives of our employees we can adequately motivate our employees to do the best they can for us. That is why we focus in this article on the motivation managers need to know and be able to stimulate their employees to maximize productivity and job satisfaction. The model we use at work is focused on the most appropriate formulation of work tasks, so that they are attractive and interesting for the employee and find a sense of satisfaction in their fulfilment [10].

The word motivation comes from the Latin word movere, which literally means something to move or move. Thus, a motive generally means something that sets things in motion [11]. The purpose of motivation is to forcefully create a positive attitude to, simply put, something, often to some performance or type of behaviour [12].

From the psychological point of view, we know two basic principles of human motivation - the principle of hedonism (socio), which deals with the fact that each action is directed to the maximum level of pleasure and avoidance of unpleasantness [9]. The second principle of psychological equilibrium is based on the fact that man's action is directed at maintaining psychological equilibrium or restoring it if it has been disturbed [13].

Approaches to motivation can be divided into two basic categories: content-theories and process-theories. In the middle of the 20th century, behavioral sciences began to promote content theories. They try to identify and also clarify the factors that motivate people and supply them with energy. Around the 1960s and 1970s, process-oriented theories appeared, although one of the oldest process-oriented theories was formulated in 1911 [14].

It is very important to understand that the human psyche at a given moment is affected not only by one motif, but by multiple motifs at a time. These can strengthen or weaken each other. The result is then the behavior of man, which arises from a combination of complex motifs. Conversely, one action can serve multiple motives [15].

The Job Characteristic Model, designed by Richard Hackman and Greg Oldham, is based on the idea that the job itself is the key to employee motivation. Boring and monotonous work suppresses motivation to do the job well, while demanding and diverse work increases motivation [16]. They came to the conclusion that, in order to be motivated, a worker needs to experience three essential psychological aspects at work to feel the meaning of his work, to associate his work with responsibility and to get information about the results of his work [17]. 
At the same time, they set out five main characteristics of work that contribute to achieving these psychological states. These are: diversity of skills used in the work, identification with tasks, significance of tasks, autonomy and feedback [18].

\section{Methodology}

To explore employee motivation, we decided to use the Job Characteristic Model, designed by Richard Hackman and Greg Oldham. All employees of the company participated in the survey. The number of respondents is 80 at the age from 28 to 54 years. All employees have completed university education. For each question we asked the respondents how much the exact statement is in relation to their work. Scores can be obtained for all five indicators, which are then combined. This number serves as an indicator of the general motivational potential of the task or work under investigation.

The number, the index, will represent how work positively or negatively affects the attitude and behavior of the employee. This number is called MPS, the motivational potential score. The formula for MPS calculation is as follows:

$$
M P S=\frac{\text { diversityof skills }+ \text { jobidentity }+ \text { jobimportance }}{3} * \text { autonomy }
$$

We use the scales to incidate whether each statement is accurate or inadeuate description or your present job. After completing the istrument, we use scoring key to compute a total score for each of the core job characteristics. The scale is following:

$$
\begin{aligned}
& 5=\text { Very descriptive } \\
& 4=\text { Mostly descriptive } \\
& 3=\text { Somewhat descriptive } \\
& 2=\text { Mostly nondescriptive } \\
& 1=\text { Very nondescriptive }
\end{aligned}
$$

According to Hackman and Oldham, a low MPS score means that employees do not have high internal motivation and that the task or task must be overworked. It can be concluded from the equation that feedback and autonomy have a greater influence on motivation than other indicators [19].

\section{Results}

Hackman and Oldham further suggest that an employee can only experience three psychological states if he has a high score for all five indicators. In the first question, we found out how accurate it is to say that respondents' work requires them to use a number of complex skills. 


\section{My job requires me to use a lot of complex skills}

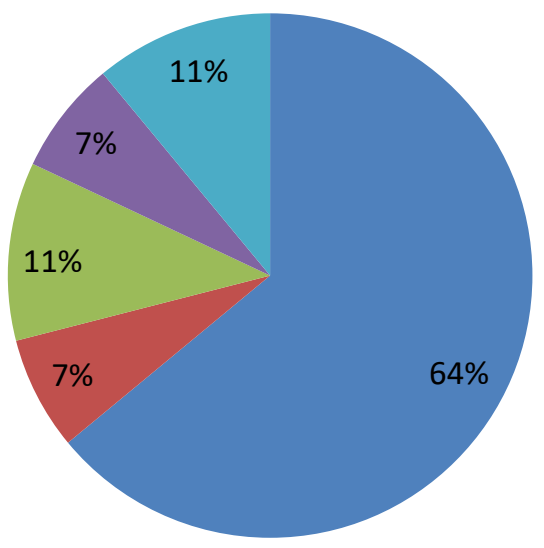

very descriptive

mostly descriptive

somewhat descriptive

mostly nondescriptive

very nondescriptive

Fig. 1. Variability of skills.

More than half exactly $64 \%$ of respondents perceive very accurately that a lot of complex skills are required in this work and $7 \%$ report mostly descriptive. We think that this is also due to the fact that there are no employees in the team that do not have a university degree in a special field. Only $11 \%$ of respondents say this perception is very inaccurate.

In the second question, we found out how they felt the time pressure by asking me to say, "My work gives me the opportunity to complete the project I started." 


\section{My job gives me the opportunity to completely finish the job (project ...) that I started}

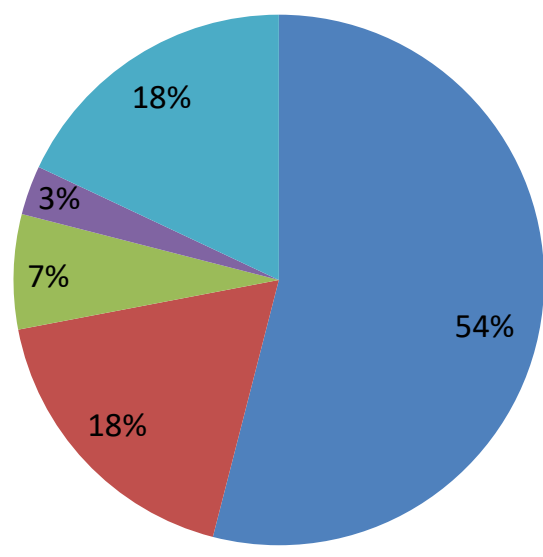

very descriptive

mostly descriptive

somewhat descriptive

mostly nondescriptive

very nondescriptive

Fig. 2. Job identity.

Most of the respondents, mostly $54 \%$, report mostly descriptive, which is very positive in terms of employee motivation. We can say that all but up to $21 \%$ of respondents who answered mostly nondescriptive and very nondescriptive positively.

The third question was to find out whether the respondent thought that many people could be affected by their work, depending on how well or badly they did it. 


\section{A lot of people can be affected by my work depending on how I will do it well or badly}

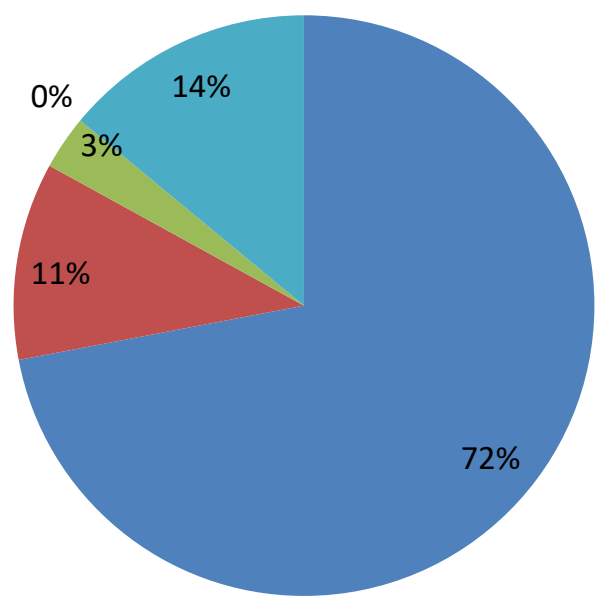

very descriptive

mostly descriptive

somewhat descriptive

mostly nondescriptive

very nondescriptive

Fig. 3. Job importance.

Absolute dominance is reported by up to $72 \%$ of respondents, and $11 \%$ report mostly descriptive, suggesting that up to $83 \%$ are aware that their motivation is influenced by a factor of responsibility and a sense of fulfillment through conscientious work.

In the fourth question, we examined the respondents' opinion on the question "whether their work provides them with independence and freedom to perform their work tasks."

\section{My job gives me independence and freedom in the performance of my tasks.}

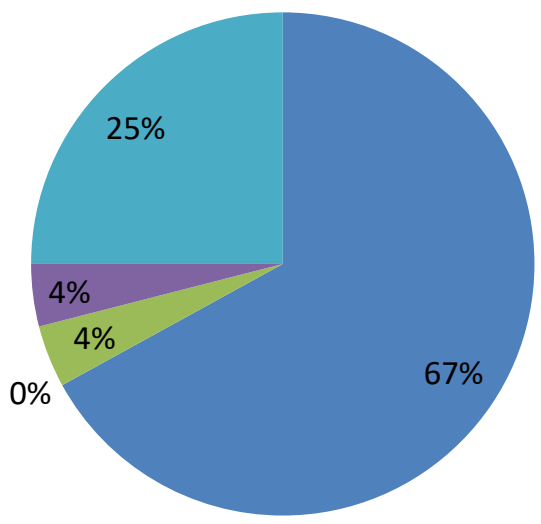

$$
\begin{aligned}
& \text { very descriptive } \\
& \text { mostly descriptive } \\
& \text { somewhat descriptive } \\
& \text { mostly nondescriptive } \\
& \text { very nondescriptive }
\end{aligned}
$$


Fig. 4. Autonomy.

As many as $67 \%$ of respondents say, in terms of freedom and independence, the term "very descriptive", while at the same time $29 \%$ say the opposite. Impartial respondents make up only $4 \%$.

In the last fifth question, we focused on the area of assessing respondents' opportunities. We found out their opinion on "fulfilling the tasks arising from their job description and whether the job provides them with opportunities to assess how well they are at work."

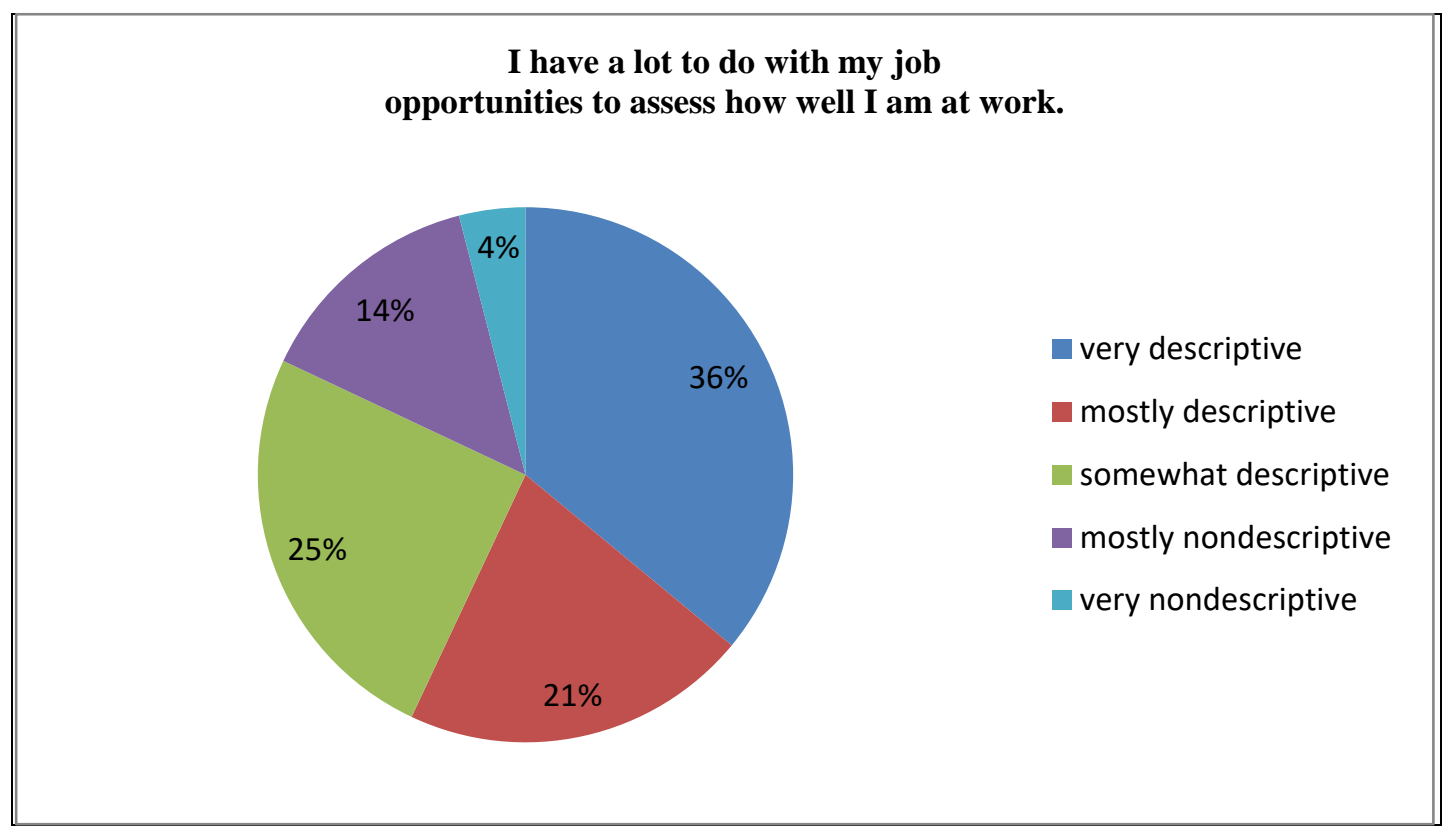

Fig. 5. Feedback.

Only $57 \%$ of respondents report that their tasks are sufficient to assess how well they are doing, and up to $25 \%$ are unable to assess whether or not they have enough opportunities to assess and $18 \%$ think they do not have enough opportunities to assess their success at work. In this case, at least sufficient feedback from the employer after each completed project would help.

We get the values into the formula in the form of the arithmetic mean for each question answered multiplied by the weight of the answer. We will therefore use the weighted average formula to calculate the average:

$$
\bar{x}=\frac{x_{1 *} w_{1}+x_{2 *} w_{2}+\cdots+x_{n *} x_{n}}{w_{1}+w_{2}+\cdots+w_{n}}
$$

In ourcase, $x_{n}$ isthefrequency of individualanswers in theOldhamHackam test, and $w_{n}$ istheweight of answersthattakevaluesfrom 1-5. In table n.1, thevalue of $x_{w}$ isdenoted as thetotalmean.

Table 1. Summary of results

\begin{tabular}{|l|l|l|l|l|l|l|}
\hline & $\begin{array}{l}\text { Diversity } \\
\text { of }\end{array}$ & & $\begin{array}{l}\text { Job } \\
\text { importance }\end{array}$ & Autonomy & Feedback & Scale \\
\hline
\end{tabular}




\begin{tabular}{|l|l|l|l|l|l|l|}
\hline & skills & $\begin{array}{l}\text { Job } \\
\text { identity }\end{array}$ & 5 & 4 & & \\
\hline $\begin{array}{l}\text { Very } \\
\text { nondescriptive }\end{array}$ & 3 & 5 & 0 & 2 & 1 & $\mathbf{1}$ \\
\hline $\begin{array}{l}\text { Mostly } \\
\text { nondescriptive }\end{array}$ & 2 & 1 & 1 & 1 & 4 & $\mathbf{2}$ \\
\hline $\begin{array}{l}\text { Somewhat } \\
\text { descriptive }\end{array}$ & 3 & 2 & 3 & 13 & 7 & $\mathbf{3}$ \\
\hline $\begin{array}{l}\text { Mostly } \\
\text { descriptive }\end{array}$ & 2 & 5 & $\mathbf{1 5}$ & 6 & $\mathbf{4}$ \\
\hline $\begin{array}{l}\text { Very descriptive } \\
\text { Withweightstotal }\end{array}$ & $\mathbf{1 4 5}$ & $\mathbf{1 3 8}$ & $\mathbf{1 5 7}$ & $\mathbf{1 2 3}$ & $\mathbf{1 3 0}$ & n/a \\
\hline Averagetotal & $\mathbf{5 , 2 7}$ & $\mathbf{4 , 9 0}$ & $\mathbf{5 , 5 5}$ & $\mathbf{4 , 3 6}$ & $\mathbf{4 , 7 3}$ & n/a \\
\hline
\end{tabular}

$$
M P S=\frac{\text { diversity of skills }+ \text { job identity }+ \text { job importance }}{3} * \text { autonomy }
$$

$=\frac{5,27+4,90+5,55}{3} * 4,36 * 4,73=108,06$

From the result we can conclude that a value above 100 represents an average value for the company, which still has a lot of room for improvement. Autonomy and feedback have a higher psychological and motivational impact.

\section{Discussion}

Motivation is in direct proportion in the job performance function. Motivated employees perform better, absent less and benefit the company. Motivated man is beneficial in any social order because of his positive influence on their surroundings. These are characteristics that a successful manager must recognize. Recognition such an aspect in the organization and putting emphasis on happy motivated employees should be the primary concern of each manager. Changes in the way you work and work processes dramatically change how we perceive work. From employees is nowadays required to master more skills than ever before while being more autonomous in their work.

These factors place high demands on management requirements. We believe that the form and structure of work (design) can have a major impact to motivate the employee, and that the manager is largely in favor of the "work design" and the psychosocial environment responsible.

There are many ways to stimulate workers, but needs are individual, so it is not an easy task. But there are motivators that apply to most workers [20]. These motivators are mentioned in the aforementioned theories, e.g. Meaningful and interesting work, matching monetary and non-monetary awards, objective feedback, good relationships in the workplace, the possibility of personal growth and job security. 
The goal of creating a functional incentive system in a company is to ensure that workers who are a key factor for the success of an organization are satisfied and deliver the best possible results at an acceptable cost to the company.

As we could see from the partial results for the individual headings, the potential for improvement is highest in the area of autonomy and feedback. Autonomy expresses freedom and independence in the performance of tasks at work. The value 4.36 is just above the average. Information companies are engaged in the integration of process mechanisms and applications in order to maximize the quality of work. To increase the autonomy in society, it would be good to reconsider too restrictive processes. However, there is a dilemma, the aim of restrictive processes is to reduce errors and increase efficiency, which translates into fewer employees able to do more with fewer errors. But are employees so limited and satisfied and motivated?

The second factor, which was on average, is the feedback factor. This factor is very important for determining the future progress of employees. Good performance is linked to career advancement and a sense of satisfaction.

Anyway, each employee is unique their skills, knowledge and skills and to be properly stimulated must be evaluated, rewarded and motivated by the individual way. It is therefore important in the company to devote a lot of time to the area, because motivation is a rather complex and lengthy process.

\section{References}

1. G.C. Wiliams, WhatJoan of Arc Can Teach Us about Human Motivation and Wellbeing.American Literary Realism 51, 2 (2019)

2. L. Taylor, J. Kliestikova, "The Operational Coherence of the Workforce-as-a-service Pattern: Digitally Mediated Service Work, the Contingency of On-demand Employment, and the Low-income Labor Market," Psychosociological Issues in Human Resource Management6, 178-183 (2018)

3. K. Valaskova, V.Bartosova, P. Kubala, Behavioural Aspects of the Financial Decision-Making. Organizacija 52, 22-32 (2019)

4. J. Kliestikova, P. Durana, M. Kovacova, Naked Consumer's Mind Under Branded Dress: Case Study of Slovak Republic. Central European Business Review 8, 1532 (2019)

5. H.R. Parola, M.B. Harari, DEL. Herst, P. Prysmakova, Demographicdeterminantsof public servicemotivation: a meta-analysisof PSM-age and -gender relationships. Public Management Review 21, 10 (2019)

6. N. Breda, J. Horak, M. Kovacova, K. Valaskova,“The Future of Work: Disruptive Business Practices, Technology-Driven Economic Growth, and Computer-Induced Job Displacement," Journal of Self-Governance and Management Economics 6, 1924 (2018)

7. A.H. Maslow, A theory of humanmotivation, Psychological Review 50, 370-396 (1943)

8. R.W. White, Motivation reconsidered - the concept of competence. Psychological Review 66, 5 (1959)

9. A. Wigfield, J.S. Eccles, Expectancy-value theory of achievement motivation. Contemporary Educational Psychology 25, 1 (2000)

10. M. Gagne, E.L. Deci, Self-determination theory and work motivation. Journal of Organizational Behavior 26, 4 (2005) 
11. E.A. Locke, G.P. Latham, What should we do about motivation theory? Six recommendations for the twenty-first century. Academy of Management Review29, 3 (2004)

12. V.V. Busato, F.J. Prins, J.J. Elshout, C. Hamaker, Intellectual ability, learning style, personality, achievement motivation and academic Access of psychology students in higher education. Personality and Individual Differences 29, 6 (2000)

13. J.G. Nicholls, Achievement-motivation - conceptions of ability, subjective experience, task choice, and performance. Psychological Review 91, 3 (1984)

14. G.J. Mogenson, D.L. Jones, CY. Yim, From motivation to action - functional interface between the limbic system and the motor system. Progress in Neurobiology 14, 2-3 (1980)

15. T. Urdan, E. Schoenfelder, Classroom effects on student motivation: Goal structures, social relationships, and competence beliefs. Journal of School Psychology 44, 5 (2006)

16. A. Haslam, et al.,The New Psychology of Leadership, Identity, Influance and Power Psychology Press (2011)

17. S. Jex, Organizational Psychology, a Scientist-practitioner Approach, John Wily \& Sons, Inc. (2002)

18. E.E. Kossek, J.S. Lambert Work and Life Integration Organizational, Cultural, and Individual Perspectives London, Lawrence Erlbaum Assotiates Publishers (2005)

19. J.R. Hackman, G.R. Oldham, Motivation through design of work - test of a theory. Organizational Behavior and Human Performance 16, 2 (1976)

20. D. Laming, Understanding Human Motivation, What Makes People Tick? Blackwell Publishing Ltd. (2004) 